\title{
Intensification of humic acid extraction from lignites
}

\author{
Tatiana Moskalenko ${ }^{1 *}$, Valery Mikheev ${ }^{1}$ and Elena Vorsina $^{1}$ \\ ${ }^{1}$ Mining Institute of the North named after N.V. Chersky, SB RAS, Yakutsk, 677018, Russian \\ Federation
}

\begin{abstract}
One of the methods of initial properties of solid fuels changing by their organic mass oxidation is considered in the paper. Creation of innovative ways of intensification of existing solid fuels processing and their adoption by industry has always been and remains an actual task. Thus the chemical process is the most important stage of raw materials processing into target products. Chemical exposure allows to optimize the technological mode, expanding the scope of control of technological process parameters and, to a certain extent, modify the properties of the resulting products. The article presents the results of experimental research of influence of preliminary oxidation on the lignite organic mass from Kharanorsk and Kangalas deposits by different chemical reagents to determine a degree of this process impact on the efficiency of their processing into humic substances. Inorganic and organic oxidizers of different concentrations were used as reagents. The greatest effect for increasing the humic acids yield was observed when using 6-10\% hydrogen peroxide for oxidation, and $10 \%$ hydrochloric acid. The results of experiments on the coal preoxidation effect can be used as a basis for the development of a new method of lignites processing into humic substances.
\end{abstract}

Keywords: oxidation, solid fossil fuels, lignite, processing, organic acids, inorganic acids, humic substances, humic acids yield.

\section{Introduction}

Creation of innovative ways for intensification of existing solid fossil fuels processing and its introduction in the industry has always been and remains an actual task. At the same time, the chemical process is the most important stage of raw materials processing into target products. Chemicals effect makes it possible to optimize the technological mode, expand the scope of process parameter control and modify the resulting products properties to a certain extent. It is also important for processing industries modernization and development of advanced mineral processing [1].

The studies conducted in recent decades have shown that the use of various reagents and methods in the pre-processing of coal raw materials allows to obtain processing products with an extended range of properties, as well as to increase the extraction of valuable components from native raw materials. However, all types of solid fossil fuels processing

*Corresponding author: labkiy@mail.ru 
lead to losses. To reduce the losses is the main task of developing new processing methods, including coal material processing into humic substances. Coal oxidation is one of the methods of this effect.

\section{Theory of Coal Oxidation}

Oxidized coal is a form of solid carbon containing oxygenated functional groups on its surface. Oxidation of solid fossil fuels can occur spontaneously (auto-oxidation) or can be performed as a directed process. Auto-oxidation takes place in natural conditions in reservoirs, during storage, when transporting. In this case, oxidation is an undesirable process because it reduces the coals quality. Targeted oxidation is the basis for coals processing to produce useful products.

Numerous studies have shown [2] that oxidation leads to changes in the elemental composition and volatile substances yield (these changes are divergent for coals of different grades), to decrease of the combustion heat, deterioration of sintering, reducing the coking products yield. At the same time, the humic acids content in lignites increases sharply, and in hard coals the secondary humic acids appear [3]. Physical factors contributing to oxidation should be considered minor. They are mainly the phenomena leading to coal grinding [4].

Aauto-oxidation processes are investigated in the aspect of studying weathering and self-ignition phenomena, as well as properties change of coal as a final product. Targeted oxidative destruction of solid fossil fuels (SFF) by various oxidizing agents was initially carried out to get to know their chemical structure, as this reaction in addition to hydrolysis allows to obtain their more simple fragments and to identify them. Later on, oxidation was considered as the basis of the technological process of obtaining various chemical products necessary for the national economy. Output and composition of products depend on genetic nature of SFF, oxidizer and process conditions [5].

Thus, oxidation of coals by reagents makes it possible to study the processes of weathering and spontaneous combustion, as well as to obtain easier substances extracted during their chemical processing. Lignites and, to a lesser extent, hard coals are most exposed to oxidation.

The difficulty in studying the mechanism of the coal organic mass oxidation is the complexity and ambiguity of the structure, composition and construction of the coal substance (organic and inorganic). This entails the complexity and ambiguity of the chemical reactions occurring during the solid fuels oxidation. In this case, the method of studying this process acquires an experimental-statistical character with the identification of general regularities. However, the study of oxidation even at this level is of great theoretical importance in the field of the coal chemical structure knowledge.

\section{Experiment}

In general, the yield of the product is the ratio of the practically obtained mass of the product to the theoretically possible mass (\%). The maximum mass of the product, which can be obtained from the feedstock, is calculated according to the reaction equation, and the content of the reagent to be transformed is taken into account. In connection with the impossibility of theoretical calculation of this indicator in relation to the fossil coals processing into humic substances due to a number of reasons (lack of formulas for both coals and humic substances, a large variety of coals, substantial variability of their properties, etc.), we take as a basis the humic acids yield according to GOST (Russian National Standard) 9517-94. Correspondingly, efficiency of reagents use and effects shows 
increase (or decrease) of indicator of humic acids yield after influences in comparison with the value defined in accordance with the above GOST [6, 7]. It allows to estimate productivity growth when introducing these methods in manufacturing, to use resources more economically and effectively, to estimate a recoupment of expenses for technology change. Thus, when introducing the intensifying process changes in technology of manufacture the expenses growth is paid off by effective and economic use of all resources (both materials, and labour).

The study of the influence of the lignite organic mass preliminary oxidation on the efficiency of their processing into humic substances was pushed by the fact that lignites are a unique natural formation, in which in the process of organic mass transformation, a specific substance - humic acids was formed. They are a significant (20-30\%), and in some cases a predominant (up to 80-90 \%) part. By their nature humic acids are highly oxidized, little or almost non-combustible organic-mineral substances. This explains the fact that lignites are mainly not energy carriers, but the sources of humic acids.

The aim of the work was to determine a degree of influence of preliminary oxidation of lignite organic mass on the efficiency of its processing into humic substances. The task of the research was to establish the influence of various oxidizing agents on the change in the lignite humic acids yield and to assess this change.

In the course of the work, the lignite samples from the Kharanorsk deposit (Zabaikalsky Krai) and Kangalas deposit (Republic of Sakha (Yakutia)) included into 2B technological group were studied as initial feed material. The yield of humic acids from lignites of the Kharanorsk deposit was rather low and varied from $6 \%$ to $17 \%$ for dry fuel with average of $11.7 \%$. The yield of free humic acids of the studied sample was (HA) ${ }^{\mathrm{f}}=6.7 \%$. The yield of humic acids from lignite of the Kagnalas deposit was average (15 - $28 \%)$. The yield of free humic acids of the studied sample was $(\mathrm{HA})^{\mathrm{f}}=21.7 \%$.

The basic experimental work was carried out according to the following methodology. The feedstock sample, crushed to a particle size less than $0.2 \mathrm{~mm}$, was filled with an oxidizing reagent, in this medium the lignite was left for the time determined by the experiment conditions. After the planned time, the sample was moved to a filter, washed with water and dried until air-dry state. After that technical analysis was carried out for determination of humidity, ash content, volatiles and humic acids yield. The ratio of oxidizer and lignite was taken on the basis of significant excess of the reagent over the feedstock and was $250 \mathrm{ml}$ per $100 \mathrm{~g}$ of lignite. The reagent remained in contact with lignite for 1 hour or 1 day.

The following oxidizing agents were chosen as the reagents in studying the oxidation effect: hydrochloric $(\mathrm{HCl})$, phosphoric $\left(\mathrm{H}_{3} \mathrm{PO}_{4}\right)$, sulfuric $\left(\mathrm{H}_{2} \mathrm{SO}_{4}\right)$ and nitrogen $\left(\mathrm{HNO}_{3}\right)$ inorganic acids; acetic $\left(\mathrm{CH}_{3} \mathrm{COOH}\right)$ and citric $\left(\mathrm{C}_{6} \mathrm{H}_{8} \mathrm{O}_{7}\right)$ organic acids, potassium permanganate $\left(\mathrm{KMnO}_{4}\right)$ and hydrogen peroxide $\left(\mathrm{H}_{2} \mathrm{O}_{2}\right)$. The results are given in the table 1 . 
Table 1. Humic acids yield ((HA) $\left.f^{d a f}\right)$ after the of oxidizers influence on lignite.

\begin{tabular}{|c|c|c|c|c|}
\hline \multirow{3}{*}{$\begin{array}{l}\text { Oxidizing } \\
\text { reagent }\end{array}$} & \multirow{3}{*}{$\begin{array}{c}\text { Concentration } \\
\text { of oxidizing } \\
\text { reagent }\end{array}$} & \multicolumn{3}{|c|}{$\begin{array}{l}\text { Humic acids (\%) yield from lignite treated with the } \\
\text { reagent with the oxidizing reagent holding time }\end{array}$} \\
\hline & & \multicolumn{2}{|c|}{ Khoranorsk lignite } & \multirow{2}{*}{$\begin{array}{c}\text { Kangalas lignite } \\
1 \text { hour }\end{array}$} \\
\hline & & 1 hour & 1 day & \\
\hline \multirow[t]{3}{*}{$\mathrm{HCl}$} & $1 \%$ & 10.2 & 10.2 & 24.6 \\
\hline & $5 \%$ & 13.5 & 10.9 & 34.2 \\
\hline & $10 \%$ & 12.3 & 11.8 & 40.0 \\
\hline \multirow[t]{3}{*}{$\mathrm{H}_{3} \mathrm{PO}_{4}$} & $1 \%$ & 9.8 & 9.2 & 28.0 \\
\hline & $5 \%$ & 10.1 & 9.3 & 30.9 \\
\hline & $10 \%$ & 12.4 & 13.6 & 37.5 \\
\hline \multirow[t]{3}{*}{$\mathrm{H}_{2} \mathrm{SO}_{4}$} & $1 \%$ & 6.8 & - & 30.9 \\
\hline & $5 \%$ & 7.6 & - & 33.0 \\
\hline & $10 \%$ & 8.0 & - & 38.9 \\
\hline \multirow[t]{3}{*}{$\mathrm{HNO}_{3}$} & $1 \%$ & 6.9 & - & 22.2 \\
\hline & $5 \%$ & 11.8 & - & 28.1 \\
\hline & $10 \%$ & 12.0 & - & 34.7 \\
\hline \multirow[t]{4}{*}{$\mathrm{CH}_{3} \mathrm{COOH}$} & $1 \%$ & 9.3 & 9.4 & 32.0 \\
\hline & $5 \%$ & 8.9 & 8.5 & 34.9 \\
\hline & $10 \%$ & 9.4 & 9.6 & 29.4 \\
\hline & $70 \%$ & 7.1 & - & 29.5 \\
\hline \multirow[t]{3}{*}{$\mathrm{C}_{6} \mathrm{H}_{8} \mathrm{O}_{7}$} & $1 \%$ & 8.1 & 8.5 & 27.5 \\
\hline & $5 \%$ & 9.5 & 10.0 & 29.3 \\
\hline & $10 \%$ & 9.3 & 8.9 & 33.3 \\
\hline \multirow[t]{3}{*}{$\mathrm{KMnO}_{4}$} & $1 \%$ & 6.6 & 7.6 & 22.8 \\
\hline & $5 \%$ & 5.5 & 5.5 & 23.2 \\
\hline & $10 \%$ & 3.6 & 4.9 & 24.2 \\
\hline \multirow[t]{3}{*}{$\mathrm{H}_{2} \mathrm{O}_{2}$} & $3 \%$ & 12.9 & 15.7 & 33.8 \\
\hline & $6 \%$ & 21.4 & 21.8 & 35.4 \\
\hline & $10 \%$ & 32.9 & 31.1 & 56.6 \\
\hline
\end{tabular}

\section{Results and discussion}

The experiments have shown that oxidation by strong (hydrochloric, nitric) and weak (phosphoric) inorganic acids is more effective for the Kharanorsk lignite than by organic acids (acetic and citric) of the same concentration, and only in some cases there was a slight increase in humic acids yield with exposure time increasing from 1 to 24 hours. For the Kangalas lignite the effect of inorganic acids on the humic acids yield was practically comparable with the effect of organic acids of the same concentrations. In this case, in general, the humic acids yield increases with the oxidizer concentration increasing. From the considered oxidizing agents with their hour action for the Kharanorsk lignite, the 
highest yield of humic acids was obtained at oxidation of phosphoric (12.4\%) and hydrochloric acids (12.3\%), for the Kangalas coal - of hydrochloric acid (40 \%).

Potassium permanganate oxidation, being a strong oxidizer, when exposed to the Kharanorsk lignite led to the opposite result - the yield of humic acids decreased, the Kangalas lignite showed a small but increased value.

The greatest increase in the humic acids yield was observed at oxidation of lignite with hydrogen peroxide at $10 \%$, concentration, thus the investigated index for the Kharanorsk lignite was increased by 4.9 times in comparison with the initial one, for the Kangalas lignite - by 2.6 times.

\section{Conclusions}

All studied reagents-oxidants, have oxidizing effect on lignite organic mass to some extent and lead to increase of humic acids yield. The greatest effect was observed when $6-10 \%$ hydrogen peroxide and $10 \%$ hydrochloric acid were used for oxidation.

It is preferable to use hydrogen peroxide for safety reasons with comparable results of these two reagents action. In addition, after oxidation, the lignite should be washed, as further humic acids extraction requires its alkaline treatment. In the case of inorganic acids (e.g. hydrochloric or phosphoric acids), lignite washing to a neutral reaction requires considerable time and a lot of water. Hydrogen peroxide does not require washing as it decomposes when heated to temperatures above $70-75^{\circ} \mathrm{C}$ or when some impurities are added, which is also an undeniable advantage.

The results of experimental studies for the effect of preliminary lignite oxidation can be used as a basis for the development of a new method of lignite processing into humic substances.

\section{References}

1. A. Yu. Cheban, G. V. Sekisov, N. P. Khrunina, A. A. Sobolev, S. M. Ugai, Systems. Methods. Technologies, 3 (27), 156-161 (2015)

2. A. A. Agroskin, Chemistry and technology of coal (Nedra, Moscow, 1969)

3. V. G. Lipovich, G. A. Kalabin, I. V. Kalechits et al., Chemistry and coal (Chemistry, Moscow, 1988)

4. M. V. Gofman, Applied chemistry of solid fuels (Metallurgizdat, Moscow, 1963)

5. I. M. Gluschenko, Theoretical Foundations of Technology of solid fossil fuels. (Metallurgia, Moscow, 1990)

6. T. V. Moskalenko, V. A. Mikheev, MIAB, 7 (30), 220-227 (2015)

7. T. V. Moskalenko, V. A. Mikheev, E. V. Vorsina, Modern high technologies 2 (3), 435440 (2016) 